\title{
TOWARDS AN OVERTHROW OF THE INTERNATIONAL ECONOMIC ORDER? (FREEDOM OF TRADE OR PROTECTIONISM?)
}

\begin{abstract}
This paper is introducing the new international landscape most probably announcing the end of globalization which was with us for almost 50 years, as well as the coming of protectionism. The new label of the next international order is "open and closed borders", in the place of the traditional distinction of left and right. The emerging political parties, becoming known as populist, appear on the international scene as a necessity in order to reduce the plagues of globalization combined with an extreme form of economic liberalism. Beside the economic causes which threaten to overthrow globalization, as the unprecedented inequality which led to an unorthodox loss in the share of labor in GDP and the establishment of a long-term stagnation, there are also strong non-economic factors as the free flow of immigration towards Europe and terrorism. The future, still unknown, could nevertheless take two different directions. First, the continuation of globalization, however under a different form, based on the realization of the Goudenhove-Kalergi project and on the concept of a world government and second the overthrow of globalization and neoliberalism.
\end{abstract}

Keywords: globalization, open-closed borders, protectionism, nationalism, welfare state, fiscal policy, immigration, terrorism, economic liberalism, supra-capitalism, inequality, unemployment, stagnation, world government

JEL: F6 


\section{INTRODUCTION}

The increasingly stronger vibrations received by the global and especially European economy threaten to overwhelm the institutional arrangements within which they have been operating over the last fifty years, and substitute them with a new status quo under totally different specifications. By this I obviously mean globalization, the end of which is suggested by all indications. Although, historically, the rotation of the international economic order $^{1}$, which occurs about every 80 years $^{2}$, is the rule, the twists we have been recently experiencing, exhibit however certain characteristics that differentiate them from their predecessors. Exactly these features are responsible for the unspecified nature of the new international landscape, while they also seem to inactivate very strong traditional distinctions, as eminently between right and left policy, thus causing a general confusion.

The pair constituting the new international economic order, as announced at least, appears to introduce a seemingly new label: that of open and closed borders. This is by no means a new distinction, but merely a verbal development of an always existing distinction between the status of free international trade, and protectionism, or even more recently, between globalization and border nationalism. Although the maintenance of the traditional distinction between deregulation and regulation of international trade seems to face no problems, these however do emerge once one attempts to attribute their accompanying options to the two traditional political parties, right and left. It is indeed customary to believe that the traditional right, is attached to economic liberalism and to all its accompanying elements, such as: the liberalization of international trade, the free movement of capital and labor, the non-intervention of the state in the economy, minimization of the tax burden, as well as the emaciation of the welfare state. On the contrary, the main characteristics of traditional left was the acceptance of the role and importance of state intervention, which extends to the regulation of international trade

\footnotetext{
${ }^{1}$ Freedom of trade or protectionism

2 François Lenglet, La $\mathrm{f}$ in de mondialisation, Librairie Arhème Fayard/Pluriel 2014, Chapitre 5
} 
treaties, to the recognition of the benefits of cooperation and complementarity of the public and private sector which are considered of equal importance, the attribution of a special importance to the services provided by the welfare state, the establishment of labor rights, perceived as the weakest factor of production, compared to capital and the imposition of progressive taxation, aiming at a more equitable distribution of income and at enabling the existence of the welfare state. Some additional but less safe distinctions between left and right are those concerning the field of economic policy options. The right, which is recognized as the most conservative, generally seeks to achieve balance in all fields. Its relationship with microeconomic policy that encourages private initiative is obvious, while less clear with macroeconomic policy. This explains the dedication of the right to austerity policies, as well as the preference for monetary policy with the exclusion of fiscal policy.

However, these indicative distinctions and economic policy preferences have been recently abolished, so as to justify the argument that the opposition between left and right has been replaced by a simple distinction between the proponents of continuing globalization, and those who are opposed to it. Indeed, in several European economies ${ }^{3}$ such as the US, the power of political parties hard or even impossible to enlist in the traditional distinction between left and right has been strengthened. These are political parties that are clearly opposed to globalization and proceed to select individual policies belonging to both traditional divisions. Apart from their obvious opposition to continuing globalization, this new hybrid political parties, some of which are close to power, constitute an amalgam, unsafe and unstable, of the individual traditional preferences of left and right wing economic policy. Therefore, it is impossible to classify them to the left or right wing platform. Thus, various groups are beginning to support that the old traditional distinction between the right and the left no longer exists.

I will indicatively refer myself to two political parties exhibiting a significant weakness as to safely categorizing them to the left or right. Let me begin with the Popular Front of Marine Le Pen in France,

\footnotetext{
${ }^{3}$ France, Hungary, Poland, Greece and Great Britain
} 
officially classified to the group of Europe's extreme right-wing parties. The party, however, not only has a chance to come to power in the next elections, if not hampered by ad hoc political blocs, but furthermore attracts the preference of the working class. This fact is indeed surprising and necessitates further analysis. How is it possible that a right-wing political party satisfies the preferences of $43 \%$ of working class voters which traditionally belong to parties of the left, while only $20 \%$ of voters honored the French Socialist party ${ }^{4}$. Let us now turn to the US, particularly to the newly emerging party of Donald Trump, which could be described as an extreme mutation of the Republican party. This party is also very close to power, but has also attracted a significant percentage of workers, to whom it has promised to heal the wounds in their standard of living caused by previous governments, namely governments of the Democratic party ${ }^{5}$. Although these two political parties complement their economic policies ${ }^{6}$ with elements drawn from their own orthodox traditional positions such as among others, reducing the tax burden, they additionally borrow some traditional positions of the left, such as trying to improve the living standards of the working class or increasing welfare state expenditure. However, the decisive factor, common not only to the two political parties indicatively selected here, but also to the rest of the newly created hybrid parties, is their intense enmity for open borders. It is precisely this enmity, which proved to be a powerful weapon attracting proponents from the newly created political parties in Europe and beyond. The ever increasing percentage of voters of these parties, which are characterized by their political opponents, as over conservative and anachronistic, turns against the maintenance of free international trade or the acceptance of refugees / immigrants on their territories, often against both of these preferences, belonging to the policy of open borders. The supporters of these political parties are convinced, not always for the same reasons that the opening of borders, whether in products or in people, is detrimental to the national economy and its people, and these are therefore perceived as nationalist parties.

\footnotetext{
${ }^{4}$ Some of them witnessed no raise in their real wages for 18 years. The Economist, 16.07.2016.

${ }^{5}$ Ibidem

${ }^{6}$ As already mentioned
} 
Irrespectively of whether these newly created political parties eventually come into power or not, they certainly mark the reversal of the current which about 50 years ago imposed globalization upon the world. The environment now is obviously very different for a number of reasons. The most important reason is undoubtedly the fact that globalization was the result of a thorough preparation of the Earth's powerful, aiming to maximize their profits, while anti-globalization is the product of the reaction of the weakest of the planet, especially those out of jobs as a result of the liberalization of international trade or those suffering a deterioration of their living standards because of the wage competition by immigrants / refugees. One should add to the above the relatives of victims of terrorist attacks and all those who, quite rightly, fear terrorism and believe that closing borders would protect them. This fundamental difference also explains how globalization was imposed, and how anti-globalization is now attempting to follow. The first, triumphantly conquered the world, as a one-way road and with the promise that all inhabitants would enjoy better days, while skeptics were characterized as backward, uneducated, enemies of progress etc ${ }^{7}$. The purest proponents of globalization are now those accusing the supporters of antiglobalization, using the same derogatory characterizations as then. However, the new international economic order which lacks the projection and strong propaganda of the media enjoyed by globalization, makes no attempt to impose itself as a one-way road or paradise like its predecessor, but only appears on the international scene as a necessity, in order to reduce the extensive and multidimensional plagues of globalization.

In Part I of this paper I will examine the causes that led to this turnover in the international arena, as well as the consequences, while Part II will attempt some predictions as to the nature of the world with (relatively) closed borders.

\footnotetext{
7 Negreponti-Delivanis, M., Mondialisation Conspiratrice, Fondation Dimitri et Maria Delivani, CEDIMES-L'Harmattan, Paris 2002, p. 43.
} 


\section{CAUSES AND CONSEQUENCES OF THE OVERTHROW}

The causes that led to the change in the international arena, so far as the latter may be foreseen, may be distinguished into economic causes and non economic causes. Their negative consequences justify the reactions boding institutional change.

\section{A. Economic causes and consequences}

\section{a) Causes}

The imminent change in the international arena can collectively be attributed to the extremities, which were gradually incorporated into the same factors that imposed globalization about 45 years ago. Which in the meantime ultimately put forward the negative consequences of globalization on almost all levels, leaving far behind any positive ones. Returning to my findings in relation to the content of globalization, put forward in 2001.8 "The environment in which the new international regime is operating revives conditions permitting the predominance of the laws of the jungle, legitimizes conditions for multilevel extortions, degrades the importance of national borders, eliminates elementary human solidarity and fosters crime in all its forms. A multitude of parallel developments, with no organic connection between them, advocates in favor of the restoration of conditions prevailing in the Middle Ages, in relation to all facets of political, economic, social, and emotional life".

Attributing to "globalization," all the plagues of mankind since the 70 s, under the main leverage of liberalization of international trade, is quite misleading. This is because the enforcement of the freedom of international trade was accompanied by "escorts", whose evolution and multifaceted consequences could not be infallibly attributed to each one of them and be distinguished in cause and effect. I refer, in particular to:

- The coexistence of globalization and the implementation of an extreme form of economic liberalism, which totally deregulated the operation of the national economies and the

${ }^{8}$ Ibidem, p.60 (Greek edition- Papazisis, $2^{\text {nd }}$ edition) 
global economy, establishing absolute anarchy and encouraging organized crime.

- The advent and especially the maturity of the postindustrial capitalist development stage, which gradually overthrew the basic theoretical principles, upon which economic theory was based. The real economy receded in the face of the virtual one, namely the stock market economy. Progress was completely separated from the prosperity of the people.

- The prevalence of a supra-capitalism which limited the power of national governments for the sake of the markets, throwing the focus on efficiency at the expense of equity. ${ }^{9}$

- An obvious decrease of the importance of national borders, due to the creation of supranational organizations like the EU, which weakened the individual national governments and minimized democracy.

- The obvious and systematic retreat of the welfare state.

This chaotic regime resulted in numerous armies of defeated, and few winners, and is the reason why the benefits of free trade are now challenged everywhere. ${ }^{10}$

\section{b) Consequences}

The consequences of this patchwork, which are mostly negative with very few positive ones can be detected by the naked eye in relation to all the decisive economic indicators. Let me mention indicatively:

a) The unprecedented inequality of distribution of the world's national wealth $^{11}$, so that $1 \%$ of the Earth's richest residents hold $45 \%$ of global wealth, and 62 people hold an income attributable to 3.5 billion of the world's poorest inhabitants ${ }^{12}$. Contributing to this abnormal situation

\footnotetext{
${ }^{9}$ Reich, R., Supercapitalisme, Vuibert, Paris, 2007, p. 10.

${ }^{10}$ Foroohar, R., After decades of consensus, the value of global free trade is being contested by the left and the right, Time, 11.04.2016

${ }^{11}$ Milanovic, B., Global Inequality-A New Approach for the Age of Globalization, 2016.

12 Cohen, P., Global rich grow richer, and richer still, International New York Times, 19.01.2015.
} 
are a large number of factors accompanying globalization, such as and among others, financial freedom, as recognized by the IMF report, based on an empirical research including 149 countries for the period 1970 to $2013^{13}$, more than double income tax in comparison to business taxation $^{14}$, generalized austerity policy implementation ${ }^{15}$, tolerance or at least ineffective regulation of tax havens, the abstention of the state from implementing redistributive policies, the underground linkages of politicians to business wealth, and naturally the declining growth of advanced economies. Although until recently, the inequality in the distribution of wealth was viewed as inevitable, as a purely social instead of an economic problem, often as a desirable development because it led to an increase in investment and employment, recent research has been sounding the alarm. In particular the IMF report ${ }^{16}$ concludes that when the richest $20 \%$ of the population increases its income by $1 \%$, the growth rate is reduced by $0.08 \%$ over the next five years, whereas an increase of $1 \%$ of the income of the poorest $20 \%$ of the population increases growth by $0.38 \%$ in the next five years. Similar are the recent findings included in a recent OECD report $^{17}$ arguing that the rising inequality during $1990-2010$ resulted in a $4.7 \%$ decline of the growth rate of OECD countries.

b) The overthrow of the constant long-term relationship between the share of labor and capital to GDP. The factor "labor" was treated as the "black sheep" following the establishment of globalization, and the virtual absence of state intervention failed to restore its gradually declining position. Thus, a significant and theoretically completely "unorthodox" loss of the share of labor in favor of capital is being recorded. This development completely upsets the underlying assumptions, upon which is based the famous neoclassical CobbDouglas production and income distribution function. It is estimated

13 Furceri, D., Lungari, P., Capital Account Liberalization and Inequality, IMF Working Paper, No WP/15/243, 11/2015

14 The highest tax for investment profits is $20 \%$, while the highest income tax reaches $39,6 \%$

15 The second UN Special Report for Greece comes to the general conclusion that austerity is against human rights

16 Titled: "Causes and consequences of inequality"

17 Titled "Because reducing inequality is to the benefit of all" 
that the share of wages declined by $5.8 \%$ in favor of profits among the G7 member states, in the period 1983 to $2006^{18}$. This adverse development should primarily be attributed to three main factors. First, to the free movement of labor and capital, second, to twists brought upon the economy by the post-industrial stage of development, and third, to new technologies ${ }^{19}$. Because of globalization, the level of workers' wages in the advanced economies competes with that of developing economies and naturally tends to drop. The well known neoclassical prediction concerning the equation of the two individual wage levels upwards may have a reasonable theoretical basis. However, because its implementation requires a long time, chances are that it will never happen, because of the rotation of the current international system every 50-80 years. The post-industrial stage, in turn, significantly reduced the need for unskilled labor reducing its remuneration.

Finally, the new technologies of the postindustrial stage decisively hampered the possibility to evaluate the productivity of labor and capital in a given production process, resulting in the traditionally "strong" factor of production, which is capital, to easily take advantage of the factor "labor", especially because state intervention is essentially turned off, mainly resulting to a generalization of part-time and generally insecure jobs. To the above reasons one should certainly add the rapid development of robotics, which progressively substitute human labor to robots.

c) The establishment of long-term stagnation, which is principally due to the maturity of capitalism, which requires increasingly smaller proportions of the two key factors for the production of one unit of output, and which further leads to lower productivity, or to productivity which is not easy to measure because it mainly concerns service products ${ }^{20}$. At the same time, however, the unfortunate choice

\footnotetext{
18 According to the IMF (2008)

19 This third factor could be absorbed by the post-industrial capitalist stage which is characterized by totally different technologies in comparison to the industrial stage

20 Negreponti-Delivanis, M., "Causes for unemployment in the post-industrial capitalist stage and a proposal for addressing it", part IA4, paper presented at the International Congress of the University of Valahia, Targoviste, October 2016 (under publication)
} 
of macroeconomic policies, such as ongoing austerity mainly within the EU, through the implementation of which it is now recognized that "no country did well"21, the attribution of primary importance to monetary stability at the expense of development, and the deterioration of the real economy in favor of the virtual one considerably worsened the situation.

\section{B. Non-economic causes and consequences}

I will mention two further causes and their consequences which are categorize as non economic, although they have connections and very strong ones with economic data. These are namely:

\section{a) The immigration current towards Europe}

The most serious problem now dividing Europe, which has many dimensions and is at the root of the creation of political parties which cannot be classified as purely right-wing or purely left-wing, is the refugee / immigrant problem. Let me mention that in France, 75-80\% of proponents of the left are favorably disposed to refugees, whereas $60 \%$ of supporters of the right and $85 \%$ of Marine Le Pen fans are reluctant to accept refugees. In spite of the principles of international $\mathrm{law}^{22}$, Europe refuses to accept the uncontrollable hordes of refugees / migrants, who are constantly arriving from the Middle East, Africa and South Asia, via the Mediterranean. For the years 2014, 2015 and 2016 these arrivals are estimated at approximately half a million. Most European countries are resorting to formal but mostly informal border closure approaches,. This is because the percentage of Europeans opposed to the arrival of refugees in their territories is significant and amounts to $56 \%$, while climbing to $81 \%$ in the Czech Republic, $78 \%$ in Latvia and Slovakia and $70 \%$ in Lithuania. Thus, although the majority of the EU Member States adopted the proposals of Mr. Junker, concerning the need to spread the number refugees among

\footnotetext{
${ }^{21}$ Announcement at an event in Messinia "Arts \& Democracy", part of the Athens Democratic Forum, where he participated as a speaker.

${ }^{22}$ In particular the Treaty of Geneva, 28 July 1971 and the protocol signed in New York on 31 January 1967, concerning refugees and obliging 145 countries to accept any person fleeing a war or persecution due to his race, religion, nationality or political views.
} 
them, as it turned out in retrospect, they had no intention to do so. The Czech Republic, Slovakia and Romania categorically refused to accept refugees on their territories, while Finland chose to be absent from that meeting ${ }^{23}$. The lack of a serious and generally acceptable program on the part of the EU in addressing this huge problem of refugees, resulted in the death or disappearance of 3072 people in the Mediterranean to date. The foreseeable culmination of the problem is expected to be the entrapment of thousands of refugees in tiny and already enormously wounded by the memoranda, Greece. Despite the fact that the European population is aging, and under the condition that Europe will be persuaded to abandon the suicidal macroeconomic policy of austerity in the near future, it will be in need of manpower. However, the simultaneous occurrence of low birth rates in Europe ${ }^{24}$, with the rise of Islam and ISIS, is leading to confusion, to a generalized xenophobia and, in particular, to a failure to adopt the right decisions. However, in spite of this low birth rate the European population seems to have increased by 1.8 million in 2015 , due to the arrival of refugees ${ }^{25}$.

\section{b)Terrorism}

Terrorism which does not represent a new phenomenon in Europe is not due to the refugee problem, but is probably enhanced and facilitated by it. Globalization, with the inconceivable jumble of excesses and scandals accompanying $i^{26}$, is mainly responsible for the rise of terrorism. Terrorism is one of the children of globalization, while the second one is fascism. ${ }^{27}$ The aggression of America, especially after the destruction of the twin towers, and the overt condemnation of a large number of countries (predominantly Muslim) collectively characterized as states of vagabonds, murderers, criminals (in 2001 by the former US President) virtually abolishes the

\footnotetext{
${ }^{23}$ Article-Discussion, «Crise migratoire en Europe »

24 In 2015, the number of births in Europe were 5.1 million while deaths 5.2, Eurostat.

${ }^{25}$ Meotti, G., Europe: The Substitution of a Population, https://www.gatestoneinstitute.org/8761/europe-population-substitution

${ }^{26}$ Negreponti-Delivanis, M., Mondialisation Conspiratrice, op.cit.

${ }^{27}$ Negreponti -Delivanis, M., The children of globalization Terrorism and Fascism, Dimitri and Maria Foundation and Papazisis Editions, Athens 2004.
} 
possibility to distinguish Islam from terrorists. The rise of racism, religious persecution, the systematic devaluation of religions and cultures are, unfortunately, an integral part of globalization, which persecutes all forms of particularity ${ }^{28}$ and is responsible for a number of wars with no apparent cause, against the "states of vagabonds", the "states of criminals", the "states of murderers". After September 11, all these states are referred to as "axis of evil"29. It was, indeed, inevitable that all these atrocities eventually outraged the whole of Islam, and not just the terrorists. Since 2003 there have been reports ${ }^{30}$ that terrorist organizations recruit new generation of terrorists on all latitudes. There is a great willingness among young people and women to thicken the ranks of terrorist Islam. Approximately 30.000 Muslims from around the world became fighters of ISIS and terrorists $^{31}$ and constitute a serious threat to the West. The recent terrorist attacks against France, Belgium and Germany have significantly increased the fans of closed borders. Terror is now hovering everywhere. In Germany only, refugees / immigrants have caused 200,000 crimes and violations ${ }^{32}$. Let me also add that under the pretext of the war against terrorism, individual freedoms and the international law are gradually being abolished since 2011 and the prohibition of use of mass destruction weapons has also been tacitly abolished. $^{33}$

As shown in Part I, there is ample evidence suggesting the overthrow of the current international economic system, namely globalization. There is, however, still nothing certain. Strong vested interests around globalization and the conspiracies surrounding it are certainly not going to let go easily of the field of succession, especially now after the exit of Great Britain from the EU has greatly weakened their position and they feel threatened on all sides.

\footnotetext{
${ }^{28}$ Ibidem, p. 486.

${ }^{29}$ Ibidem, p. 480.

30 Don Van Natta, Butler, B., Qaeda Recruiting drive draws on Iraq crisis", International Herald Tribune, 17.3.2003

31 Mahbubani, K., Summers, L., H., The Fusion of Civilizations, Foreign Affairs, May-June 2016, pp. 126.

${ }^{32} \mathrm{https}$ ://fr.wikipedia.org/wiki/Crise migratoire-en- Europe \#cite note-H-all

33 Ibidem, p. 650.
} 


\section{THE NEW WORLD COMING}

Part II will consider two scenarios concerning the nature that will ultimately be imposed on earth. Continuous globalization is the first scenario, while the protection of national borders is the second. These two scenarios will constitute fields A and B .

\section{A. Globalization will continue}

Neoliberals are very keen for globalization to continue and in spite of its wretched consequences, they continue to stress its advantages and refuse to see the disastrous consequences that threaten to lead even to a third World War. For the umpteenth time they insist on repeating the well known views of globalization supporters, namely that it is the system that ensures the highest possible income and enriches the economies adopting it, that international organizations such as NATO and the EU are valuable for the US and Europe, that the war against terrorism requires broad coalitions. They proceed to add that the negative effects of globalization summarized in conclusion that it "has few winners and many losers" can be addressed through a successful treatment of immigrants / refugees, with the intensification of the Welfare State, investments in infrastructure etc., i.e. measures never adopted up to now by the neoliberal policy. It is certain that they are losing ground however and that the power of the supporters of closed national borders who want to retake control of their borders, have a choice concerning the adoption of the most appropriate macroeconomic policy for the particularities of their individual economies, as well as salvage their religion, history and cultural heritage is simultaneously rising. My belief is that we are very close to the overthrow of globalization ${ }^{34}$, but as the future is uncertain, it is imperative to investigate what awaits our descendants, if it continues.

\footnotetext{
${ }^{34}$ As already argued in my paper at the International Congress in Croatia, 4/2015, "La fin de la mondialisation"? (under publication)
} 
a) The realization of the Goudenhove-Kalergi project: The Genocide of the peoples of Europe project ${ }^{35}$

The Goudenhove-Kalergi plan could be the product of young man's active imagination, or it could be a conspiracy for the genocide of the people of Europe. In 1922 Goudenhove-Kalergi, a gifted young man of aristocratic origin, founded the "Paneuropa" movement in Vienna, aspiring at establishing a new international order, around the unification of Europe, led by the United States. European integration would be the first step towards the creation of a world government. In spite of the fact that this project was known by very few people and then forgotten for a little less than a century, for the insiders, Richard Goudenhove Kalergi is regarded, and rightly so, as the founder of United Europe. Even smaller is the number of those aware that the plan "Paneuropa" hid an evil prediction for the future of Europe: its disappearance. On the book cover 'Praktischer Idealismus», Kalergi in fact argues that the inhabitants of the future "United States of Europe" would have no relation to the old peoples of the continent, but would be a kind of sub-humans produced through miscegenation. He advances without scruples the view that Europeans should be mixed with Asian and African tribes, so as to produce a race with no quality, entirely under the control of America. Kalergi explains: "The man of the future will be of mixed race. Today's tribes and races will gradually disappear due to the elimination of space, time, and prejudice. The Eurasian- african race of the future, similar in appearance to the ancient Egyptians, will replace the diversity of peoples and the diversity of individuals." The elimination of nations and peoples can be achieved among other factors, according to Kalergi, through migration. The revival of this dark plan is directly linked to the recent and unregulated influx of immigrants and refugees in Europe, belonging to the races preferred in the Kalergi plan. But, again, this could be a mere coincidence. However, the plan is framed by events that are difficult to be treated any longer as "coincidences" I have selected the following extracts from the article in question:

\footnotetext{
35 The article was translated from Italian and edited by Eleftherios Anastasiadis. It has been posted on the site «Identità». Posted by August 8, 2015 from blogspot http://theodotus.blogspot.gr)
} 
- First, in honor of Coudenhove- Kalergi, a European prize was established, awarded every two years, to Europeans recognized for their contribution to the promotion of the Kalergi Plan. The winners so far are Angela Merkel and Herman Van Rompuy.

- Secondly, it is well known that the US are constantly encouraging Europe through the United Nations, to accept millions of immigrants, to thereby solve the low birthrate and aging problem of the population. The article in question cites a UN report from January 2000 titled "Replacement Migration: A solution to declining and aging populations", which states that by 2025 Europe will need 159 million immigrants. Amazing indeed is the exact number which in combination with all the above, automatically refers to the existence of a premeditated plan. The columnist of the article in question reasonably wonders why the UN do not advise Europe to adopt other solutions, such as family support programs, similar to those applied by the French for decades, but rather urge her to submit to its genocide plan.

- Third, the following statement by G. Brock Chisholm, former director of the World Health Organization (OMS), referring to the article in question, strengthens the suspicion as to the existence of a dark plan against Europe's sustainability, based on Kalergi views. The statement reads as follows: "What people in all places should do is to adopt the restriction of births and proceed to mixed marriages (between different races), in the aim of creating a single race in a world directed by a single central authority."

- Fourth finally, it is difficult to avoid connotations between the likely course of the implementation of the Kalergi Plan and the tendency of some European economies, including Greece, to abolish the teaching of religion in schools, to undermine the teaching of their national language, or to alter the country's history in school textbooks and devalue national symbols and historical victories which sustain national pride and national identity. 


\section{b) Parallel findings and warnings concerning the end of Europe}

The combination of aging / low birth rate in Europe and unregulated migratory flow is the basis of findings, which are not associated with the Kalergi plan, but come to the same conclusion, namely the extinction of Europe. Let me mention the following, included in an article by Giulio Meotti ${ }^{36}$ :

- Europe's population is reduced by about two million a year, and steadily replenished by immigrant population. David Coleman ${ }^{37}$ describes this substitution as follows: "The suicidal decrease of Europe's low birth rate, combined with rapidly increasing numbers of immigrants will mutate European culture. The decreasing birth rate of indigenous Europeans coincides in fact with the institutionalization of Islam in Europe and the renewal of the islamization of Muslims".

- Lord Sacks said recently: "The declining birth rate can mean the end of the West." Europe, as it ages no longer renews its generations, but welcomes instead massive immigration from the Middle East, Africa and Asia, which will replace the native Europeans and bring cultures with radically different values concerning relationships between genders, political power, culture, economy and the God and human connection.

- Cardinal Raymond Leo Burke predicted that "Islam will dominate over Europe because of faith and birth rate."

In exactly the same way they face the problem of the destruction of the environment, neoliberals passively face the problem of migration: with the expectation, that the "invisible hand" will restore order. In the meantime through a series of arguments, which under normal circumstances are true, such as that Europe will need increased manpower in the near future or that mixed societies ensure a better quality of life, they attempt to justify the fact that they appear friendly towards unregulated immigrant arrivals.

\footnotetext{
${ }^{36}$ Europe: The Substitution of a Population, op.cit.

${ }^{37}$ In the study titled: Immigration and Ethnic Change in Low -Fertility Countries: A third Demographic Transition
} 
So, "one generation later Europe will be unrecognizable. The European people largely realize that their culture is mainly threatened by a casual liberalism, an ideology covered under the guise of freedom which aims to demolish all ties binding a man to his family, his relatives, his work, history, religion, language, his Nation, his freedom. This attitude seems to stem from an inertia leading to indifference as to whether Europe will succeed or be destroyed, whether our civilization will disappear, drowned in the national chaos, or be flooted by a new religion coming from the desert"138. Under the light of what is mentioned above, the free flow of immigrants / refugees should be seen as the last stage, after globalization and pure liberalism, of the progress towards the establishment of a global governance of our planet ${ }^{39}$

\section{B. Is globalization coming to an end?}

The second and most probable development is the return of protectionism in Europe and worldwide. As seen above, many signs point to the end of globalization, at least in its pure form imposed in the 70 s, accompanied by unbridled neoliberalism. The recent lack of ideology of those opposed to globalization is now beginning to shift towards the search of their lost identity: nation, religion, culture. Moreover, people from America to Egypt appear frustrated by globalization, and the fact that its positive results are not equitably distributed, but accumulated at the top. If this forecast proves correct, its consequences are not to be expected immediately but gradually, because the supporters of globalization are still powerful, despite the huge problems now facing their ideology. Their effort to prevent the overthrow of the international regime is twofold: In the first place, they engage in analysis and measurements as to the extent GDP shall be reduced in case of imposition of restrictive measures, and secondly, they respond to the negative effects of globalization, such as, among others, the loss of jobs, arguing that the citizens gain by acquiring cheap products. It is obvious however that the slowdown of world trade has started long ago, and the ongoing crisis is not in itself able to

\footnotetext{
${ }^{38}$ Meotti, G., op.cit.

39 Negreponti-Delivani, M., The cold-blooded murder of Greece, Delivani Foundation and Ianos editions, Athens 2014,
} 
interpret this change. The income elasticity of transactions was equal to 2 in 1990 and has now dropped to unity ${ }^{40}$. The revitalization of international trade is attempted through efforts to sign a new trade and investment treaty between America and Europe (TTIP), which however encounters many difficulties, and rightly so, as it exhibits numerous dark aspects. ${ }^{41}$

The circumstances of the coming new world are expected to be charged with unprecedented difficulties, whose treatment will prove to be hard if not impossible, in the context of globalization. This is because globalization and the EU offer collective solutions, while the particularities of each national economy require ad hoc approaches. It is also due to the fact that the maintenance of liberalism together with globalization, will not allow for national improvements in income distribution, alleviating unemployment, maintaining the rights of workers. Let us now turn to a brief look at the new problems that come with adulthood in the 21 st century:

- Terrorism. It would be naive to argue that, in the future, the West will be able to eliminate terrorism on the part of Isis. There are thousands, determined to sacrifice their lives for an ideology which as sick as it is, as absurd, fanatical and brutal, has nevertheless recruited thousands of fans, and not only Muslims, both within and outside Europe, who are constantly trained and employ completely different aggressive approaches every time. I believe that no particular explanation is necessary to support the impossibility of dealing with them in the context of open borders, irrespectively of the training of special services of each country. Terrorism will certainly not be easy to handle even with protected borders. It will be easier however. This is because controlling incoming flows will be easier, as well as monitoring those already within the territory.

- Inequalities. The pursuit of productivity growth, which is a primary objective of the advanced economies, does not address

\footnotetext{
40 "Le grand ralentissement des échanges internationaux", Alternatives Economiques, No 352, Décembre 2015.

${ }^{41}$ What is TTIP? And six reasons why the answer should scare you

Have you heard about TTIP? If your answer is no, don't get too worried; you're not meant to have
} 
the problem of income distribution inequality, which is constantly rising on the national level ${ }^{42}$. This is because the decline of state intervention encourages factors that "make the rich richer and the poor poorer." Generalizing, it can be concluded that this adverse development is due to the nonenforcement of income redistribution policies, mainly in the form of fiscal policy. The latter has virtually disappeared from modern economies, given that the preference for the neoliberal view is limited to the implementation of monetary policy. The ability of individual states to choose specific macroeconomic policies most appropriate for their specific characteristics could also include the application of measures to reduce inequalities.

- Unemployment. Mature capitalism requires an increasingly smaller amount of labor to produce a given production unit. The advent of robotics, on the other hand, disables millions of workers around the globe, with their very few chances of their being employed in jobs which might be created but only after some time. It is forecasted that not even specialized jobs will be saved because they can be easily replaced by robots ${ }^{43}$. It is urgent to explore ways to address this situation, which can be the following two: first, to drastically reduce full-time working hours, so that total working hours can be allocated to the whole of the available labor force ${ }^{44}$ and second, the introduction of a basic income for the unemployed or for $\mathrm{all}^{45}$. The decision for this second solution is clearly easier on the national level, rather than in the global economy.

\footnotetext{
42 Despite being limited on the international level, especially because of the introduction of China to free trade.

${ }^{43}$ Porter, E., New technology poses new peril to array of jobs, International New York Times, 08.06.2016.

${ }^{44}$ Negreponti-Delivanis, M., Les causes du chômage dans le stade post-industriel du capitalisme suivi d'une proposition pour les combattre, Exposé au Congrès Internationale de l'Université Valahia, en Octobre 2016.

${ }^{45}$ Porter , E., Manjoo, F., An end to work? A debate over a future without jobs, International New York Times, 10.03.2016.
} 
- Economic stagnation ${ }^{46}$. All indications suggest that the world and primarily Europe, have entered into secular stagnation, as predicted and described by Alvin Hansen ${ }^{47}$. Some countries are already resorting to desperate measures, such as imposing zero or even negative interest rate, and according to America's proposal, drop large dollar amounts by helicopter to revive demand. Obviously, most of the responsibility should be attributed to the long-term imposition of austerity policies, primarily in Europe, and to the abolition of fiscal policy, which reduced to a certain degree the consequences of the economic cycle. It is clear that this stagnation has more severe unfavorable consequences for the less developed economies of the South. Thus, the possibility for these economies to develop their own macroeconomic policy, away from the constraints and requirements of globalization and the EU-eurozone is particularly important.

\section{CONCLUSION}

Economic unions among countries undergoing different stages of development and distinguished by particular characteristics when subject to a common macroeconomic policy, usually fail. The way in which the failure occurs is almost always identical. Namely, those of the original promises implemented mainly favor the most powerful members of the unions and turn against the weaker. The prospect of global governance, sometimes hovering as a promise, but usually as a threat, is dangerous because with its prevalence it will destroy whatever man loves the most since the beginning of time: the homeland, language, traditions. It is argued by the proponents of globalization that all these attachments are backward and should be overcome and that the whole of the Earth's population be subject to the same rules. But, if these materialize, life would be very monotonous and colorless and naturally one could not exclude the existence of enormous risks such as the revival and generalization of

\footnotetext{
46 Negreponti-Delivanis, M., Negative interest rates - Absolute despair improvises the economy, Rapport à l'Académie des Sciences Roumaines, 2016.

47 'Economic Progress and Declining Population Growth", Psident' s speech 1938
} 
slavery for the majority of the Earth's population. For all these reasons in addition to those mentioned above, it would be desirable to restrict globalization in combination with the revival, to some extent, of national borders. Such an evolution seems to be the most likely because, as shown above, the common global opinion is in favor of imposing controls on extreme forms of globalization and liberalism.

\section{REFERENCES}

1. Cohen, P., Global rich grow richer, and richer still, International New York Times, 19.01.2015

2. Don Van Natta, Butler, B., Qaeda Recruiting drive draws on Iraq crisis", International Herald Tribune, 2003

3. Furceri, D., Lungari, P., Capital Account Liberalization and Inequality, IMF Working Paper, No WP/15/243, 11/2015

4. Lenglet, F., La $\mathrm{f}$ in de mondialisation, Librairie Arhème Fayard/Pluriel, 2014.

5. The Economist, 16.07.2016.

6. Le grand ralentissement des échanges internationaux", Alternatives Economiques, No. 352, Décembre 2015.

7. Negreponti-Delivanis, M., Mondialisation Conspiratrice, Fondation Dimitri et Maria Delivani, CEDIMES-L'Harmattan, Paris, 2002.

8. Negreponti -Delivanis, M., The children of globalization Terrorism and Fascism, Dimitri and Maria Foundation and Papazisis Editions, Athens 2004.

9. Negreponti-Delivani, M., The cold-blooded murder of Greece, Delivani Foundation and Ianos editions, Athens 2014.

10. Negreponti-Delivanis, M., "Causes for unemployment in the post-industrial capitalist stage and a proposal for addressing it", part IA4, paper presented at the International Congress of the University of Valahia, Targoviste, October 2016.

11. Negreponti-Delivanis, M., Les causes du chômage dans le stade post-industriel du capitalisme suivi d'une proposition pour les combattre, Exposé au Congrès Internationale de l'Université Valahia, en Octobre 2016.

12. Mahbubani, K., Summers, L., H., The Fusion of Civilizations, Foreign Affairs, May-June 2016. 
13. Negreponti-Delivanis, M., Negative interest rates - Absolute despair improvises the economy, Rapport à l'Académie des Sciences Roumaines, 2016.

14. Meotti, G., Europe: The Substitution of a Population, https://www.gatestoneinstitute.org/8761/europe-populationsubstitution

15. Milanovic, B., Global Inequality-A New Approach for the Age of Globalization, 2016.

16. Porter, E., New technology poses new peril to array of jobs, International New York Times, 08.06.2016.

17. Porter, E., Manjoo, F., An end to work? A debate over a future without jobs, International New York Times, 10.03.2016 